\title{
RANCANG BANGUN SISTEM SMARTHOME BERBASIS INTERNET OF THINGS DENGAN NODE MCU DAN GOOGLE ASSISTANT DI SMARTPHONE ANDROID
}

\author{
Muhamad Suryanto ${ }^{1}$, \\ Program Studi Teknik Elektro Universitas Muhammadiyah Palembang \\ Email: muhamadsuryanto@gmail.com \\ Feby Ardianto ${ }^{1}$ \\ Program Studi Teknik Elektro Universitas Muhammadiyah Palembang \\ Email: ardianto.feby@gmail.com \\ Bengawan Alfaresi ${ }^{1}$ \\ Program Studi Teknik Elektro Universitas Muhammadiyah Palembang \\ Email: bengawan_alfaresi@um.palembang.ac.id
}

\begin{abstract}
S : Science and technology that continues to develop have a major influence in completing work. By using Internet of things (IoT) technology, electronic devices will have the ability to communicate with each other, send and receive data through an internet network connection. The science of internet of things can be applied to monitoring or controlling systems in certain environments such as Smarthomes. Smarthome systems are currently mostly made only based on applications, even if there is a Smarthome with voice commands such as Google assistant and even then the price will be expensive and one device can only control one device, therefore in this research, Smarthome Design Based on the Internet of Things Using NodeMcu is carried out. With Google Assistant on Android Smartphone. In this study there are several stages, namely the stage of determining hardware and software, designing, programming, and finally testing. In this research, NodeMcu is needed as a microcontroller, which functions to control electrical equipment, process data, send and receive data to the Blynk server. IFTTT itself acts as a liaison between 2 platforms, namely Blynk and Google Assistant. The final result of this research is a Smarthome system that can be controlled by voice commands or through an application on an Android phone Keywords: Smarthome, Voice Command, IoT, NodeMCU..
\end{abstract}

ABSTRAK: Ilmu pengetahuan dan teknologi yang terus berkembang memberikan pengaruh besar dalam menyelesaikan pekerjaan. Dengan menggunakan teknologi Internet of things (IoT) perangkat-perangkat elektronik akan memiliki kemampuan untuk saling berkomunikasi, saling mengirim dan menerima data melalui koneksi jaringan internet. Imu internet of things dapat diterapkan pada sistem monitoring atau pengendali pada lingkungan tertentu seperti Smarthome. Sistem Smarthome pada saat ini kebanyakan dibuat hanya berbasis aplikasi saja, kalaupun ada Smarthome dengan voice command seperti Google assistant itupun harganya akan mahal dan satu perangkat hanya bisa Mengontrol satu alat saja, oleh karena itu dalam penelitian ini dilakukan Perancangan Smarthome Berbasis Internet Of Things Menggunakan NodeMCU Dengan Google Assistant Di Smartphone Android. Pada penelitian ini terdapat beberapa tahapan, yaitu tahap penentuan hardware dan Software, perancangan, pemprograman, dan yang terakhir pengujian. Pada penelitian ini, dibutuhkan NodeMcu sebagai mikrokontroller, yang berfungsi untuk mengendalikan peralatan listrik, mengolah data, mengirim dan menerima data ke server Blynk. IFTTT sendiri sebagai penghubung antara 2 buah platform yaitu Blynk dan Google Assistant. Hasil akhir dari penelitian ini adalah sistem Smarthome yang dapat dikendalikan Perintah suara maupun melalui aplikasi di handphone Android

Kata Kunci: Smarthome, Perintah Suara, IoT, NodeMcu.

\section{PENDAHULUAN}

B erkembangnya ilmu pengetahuan dan teknologi saat ini memberikan pengaruh besar dalam menyelesaikan pekerjaan. Ilmu yang diterapkan pada mesin dan elektronika dapat diselesaikan dengan lebih efektif dan efisien. Berkembangnya ilmu pengetahuan dan teknologi juga mendorong manusia untuk terus berpikir kreatif tidak hanya menemukan sesuatu yang baru, tapi juga memaksimalkan kinerja suatu teknologi [1]. Perkembangan teknologi yang makin pesat memungkinkan terbentuknya sistem yang saling terhubung melalui koneksi internet sebagai medianya.

Internet of things (IoT) ialah teknologi yang memungkinkan perangkat-perangkat elektronik dapat memiliki kemampuan untuk saling berkomunikasi, saling mengirim dan menerima data melalui jaringan internet, IoT dapat diterapkan pada sistem monitoring atau pengendali pada lingkungan tertentu seperti smarthome [2].

Konsep smarthome dapat memungkinkan pengendalian peralatan elektronik dengan menggunakan perintah dari mana saja, dimana manusia tidak perlu bergerak mendekati sebuah peralatan rumah tangga hanya untuk menghidupkan atau mematikan peralatan tersebut, melainkan dapat dikendalikan dari jarak jauh salah satu nya dapat melalui perintah suara dari penghuni rumah tersebut [3].

\footnotetext{
1 Program Studi Teknik Elektro Universitas Muhammadiyah Palembang
} 
Smartphone yang banyak dipakai oleh masyarakat adalah smartphone dengan sistem operasi Android. Salah satu fitur yang disediakan smartphone Android adalah speech command. Speech command merupakan proses identifikasi untuk mengenali kata yang diucapkan oleh seseorang. contohnya Google Assistant. Selain itu smartphone dengan koneksi ke jaringan internet dapat digunakan untuk mengendalikan mikrokontroler yang juga terhubung dengan internet [4].

NodeMCU merupakan modul mikrokontroler yang didesain dengan konektivitas jaringan Wifi didalamnya. NodeMCU berbasis bahasa pemograman Lua namun dalam penerapannya dapat menggunakan Arduino IDE untuk memprogramnya, sehingga menjadi lebih simple dalam penggunaannya [5] selain itu NodeMCU lebih murah dibandingkan mikrokontroler yang lain dengan fungsi yang relatif sama.

Sistem Smarthome pada saat ini kebanyakan dibuat hanya berbasis aplikasi saja, kalaupun ada Smarthome dengan voice command sperti Google assistant itupun harganya akan mahal dan satu perangkat hanya bisa mengontrol satu alat saja, oleh karena itu dalam penelitian ini dilakukan Perancangan Smarthome Berbasis Internet Of Things Menggunakan NodeMcu Dengan Google Assistant Di Smartphone Android.

\section{A. Internet of Things}

\section{TINJAUAN PUSTAKA}

Internet of Things (IoT) adalah konsep yang memanfaatkan konektivitas internet, dengan berkembangnya infrastruktur internet, bukan hanya smartphone atau komputer saja yang bisa terhubung dengan internet. Namun semua benda elektronik akan dapat terkoneksi dengan internet [6].

Teknologi IoT untuk saling terhubung berkomunikasi ini membuat IoT dapat diterapkan pada segala bidang. Contohnya di bidang pertanian, bidang kesehatan, bidang smart building, dan sebagainya, IoT dalam bidang kelistrikan dapat digunakan untuk memonitor penggunaan energi listrik. IoT juga dapat digunakan di bidang Smarthome, automation, industri, transportasi lainnya. [7]

\section{B. Blynk}

Blynk adalah platform yang memungkinkan membuat Interface untuk proyek IoT baik Hardware dari Smartphone seperti Android dengan kinerja yang sangat cepat. Aplikasi Blynk memiliki banyak fitur pada Widget seperti mengatur tombol, grafik, timer, terminal, dan lainnya. Widget dapat mengendalikan pin pada mikrokontroler atau menampilkan data dari sensor. Blynk sangat cocok untuk proyek yang sederhana, karena Blynk dapat menghemat waktu dan sumber daya yang diperlukan ketika membangun aplikasi IoT. Blynk memudahkan dalam pengodingan sehingga tidak diperlukan coding yang sangat panjang [6].

Blynk memiliki tiga komponen utama, yaitu Aplikasi, Server, dan Libraries. Blynk server berfungsi untuk menangani semua komunikasi diantara aplikasi di smartphone. Jenis server yang bisa menggunakan Blynk yaitu Cloud atau server sendiri (private) [5].

\section{Smarthome}

Smarthome adalah sebuah konsep dimana di dalam rumah terdapat sistem yang berjalan secara otomatis dan dapat dikendalikan dari jauh untuk meningkatkan kenyamanan dan keamanan penghuni hunian. Smarthome merujuk pada rumah yang memiliki sistem otomatis yang canggih. Smarthome menghubungkan sistem tersebut kedalam satu jaringan yang terintegerasi dengan kontrol yang terpusat, salah satu tujuan dari Smarthome adalah meningkatkan keamanan dan kenyamanan penghuni rumah dengan kebutuhan masing masing. Melalui sistem Smarthome penghuni rumah dapat mengontrol sistem - sistem yang terhubung sesuai dengan kebutuha, perangkat yang ada di dalam Smarthome dapat terhubung dengan menggunakan berbagai cara salah satunya menggunakan tekonologi seperti WiFi [2].

Secara umum smarthome memerlukan 3 syarat agar bisa disebut smart, yaitu 1. Internal Network: berupa kabel, wireless 2. Intelligent Control : berupa gateway untuk mengelola sistem 3. Home Automation : mengatur dan mengelola [7].

\section{NodeMCU}

NodeMCU adalah sebuah platform IoT yang bersifat open source. Terdiri dari perangkat keras dengan System On Chip (SoC) ESP8266-12, juga firmware yang menggunakan bahasa pemrograman scripting Lua. NodeMCU sebenarnya mengacu pada firmware yang digunakan dari pada perangkat kerasnya. NodeMCU dapat dianalogikan sebagai board Arduino-nya ESP8266. NodeMCU telah menggabungkan ESP8266 ke dalam sebuah board dengan berbagai fungsi seperti mikrokontroler umumnya, ditambah juga dengan kemampuan akses terhadap Wifi juga fitur komunikasi USB to Serial sehingga untuk memprogramnya hanya diperlukan sebuah kabel data mikro USB. Secara umum ada tiga produsen NodeMCU yang produknya banyak beredar yaitu: DOIT, Amica, dan Lolin/WeMos. Dengan beberapa jenis varian board yang diproduksi yakni Versi1, 
Versi2 dan yang terbaru saat ini adalah Versi3 [8].

NodeMCU adalah sebuah pengembangan dari ESP8266 dengan firmware yang berbasis e-Lua, pada NodeMCU dilengkapi dengan micro usb port yang berfungsi untuk memasukan program ke NodeMcu maupun sebagai sumber listrik untuk menyalakan NodeMCU. Salain itu pada NodeMCU mempunyai dua buah tombol yaitu tombol reset dan flash. NodeMCUpada dasarnya menggunakan bahasa pemograman Lua yang merupakan bahasa default dari ESP8266. Bahasa Lua memiliki logika dan susunan pemograman yang mirip dengan bahasa $\mathrm{C}$ hanya ada perbedaan pada sintak. Jika ingin menggunakan bahasa Lua maka dapat menggunakan Lua uploder maupun Lua loader.

Selain dengan Bahasa Lua NodeMCU juga support dengan Software Arduino IDE dengan melakukan sedikit perubahan pada board manager pada Arduino IDE. Sebelum digunakan board ini harus di-flash terlebih dahulu agar dapat mendukung tool yang digunakan. Jika menggunakan Arduino IDE dapat menggunakan firmware yang cocok seperti firmware dari Ai-thinker yang mendukung AT Command. Untuk penggunaan tool Lua loader firmware yang digunakan adalah firmware NodeMCU [9]

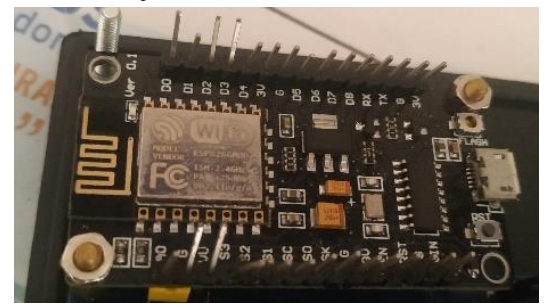

- Gambar 1. NodeMCU

\section{E. Arduino IDE}

Arduino IDE (Integrated Development Environment) merupakan perangkat lunak yang disediakan oleh Arduino untuk melakukan berbagai proses yang berkaitan pemprograman Arduino. Arduino IDE adalah perangkat lunak open source sehingga dapat digunakan pula untuk pemrograman NodeMCU seperti membuat perintah atau source code, melakukan pengecekan kesalahan, kompilasi, upload program, dan menguji hasil kerja NodeMCU melalui serial monitor. Program yang ditulis dengan Software Arduino IDE disebut sebagai sketch. Sketch ditulis dalam suatu editor teks dan disimpan dalam file dengan ekstensi .ino. IDE ini juga sudah didukung oleh berbagai sistem operasi saat ini seperti Windows, Mac, dan Linux [1].

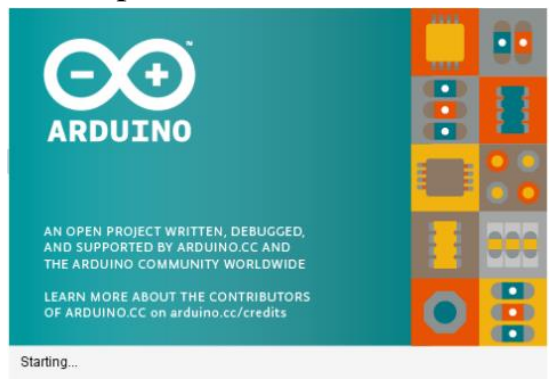

- Gambar 2. Arduino IDE

\section{F. $\quad$ Android}

Android adalah sistem operasi berbasis Linux yang dirancang untuk perangkat layar sentuh seperti Smartphone dan tablet. Android pertama dikembangkan oleh sebuah perusahaan Android.Inc., yang dukungan oleh Google. Kemudian Google membeli Android.Inc. pada tahun 2005. Sejak tahun 2008, Google terus menerus dan secara bertahap melakukan pembaruan pada sistem Android untuk meningkatkan kinerja dari sistem operasi Android tersebut, Google juga menambahkan fitur-fitur baru, memperbaiki bug yang ada pada versi Android sebelumnya. Setiap versi yang Android dirilis akan dinamakan berurutan secara alfabet dengan berdasarkan nama sebuah makanan penutup atau pencuci mulut. Berikut adalah versi sistem operasi Android: Apple Pie, Banana Bread, Cupcake, Donut, Éclair, Froyo, Gingerbread, Honey Comb, Ice Cream Sandwitch, Jelly Bean, Kitkat, Lollipop, Marshmallow, Nougat, Oreo, Pie [10].

\section{G. Google Assistant}

Google Assistant atau Asisten Google adalah asisten virtual dengan Artificial Intelligent (kecerdasan buatan) yang dikembangkan oleh Google. Google Assistant saat ini tersedia untuk smarpthone berbasis Android dan perangkat rumah pintar seperti Google Home. Google Assistant dapat berinteraksi dalam percakapan dua arah. Pengguna dapat berinteraksi dengan Google Assistant melalui suara, input keyboard juga didukung dan dapat digunakan untuk disabilitas atau saat penangkapan suara kurang baik. Google Assistant dapat diperintahkan banyak hal [1], seperti mencari sesuatu di Internet, menyetel alarm, menjadwalkan acara, 
mencarikan musik dan video, hingga mengendalikan perangakat elektronik yang sudah tersambung dengan sistemnya.

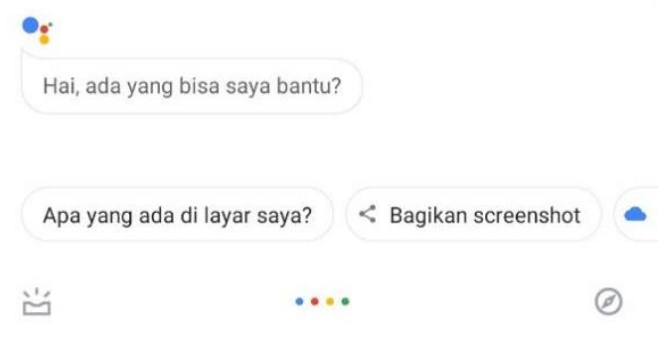

\section{H. If This Then That (IFTTT)}

- Gambar 3. Tampilan Google Asisstant

IFTTT atau If This Then That adalah sebuah aplikasi gratis untuk menghubungkan dua buah platfrom. Contohnya pengguna mendapatkan pesan singkat (sms) setiap ada email baru yang masuk, dapat dilakukan dengan menggunakan IFTTT. Pada penelitian ini IFTTT (If This Then That) digunakan untuk menghubungkan antara Blynk dengan Google Assistant. IFTTT mengambil data masukkan dari Google Assistant dan dikirim ke Blynk. [1].

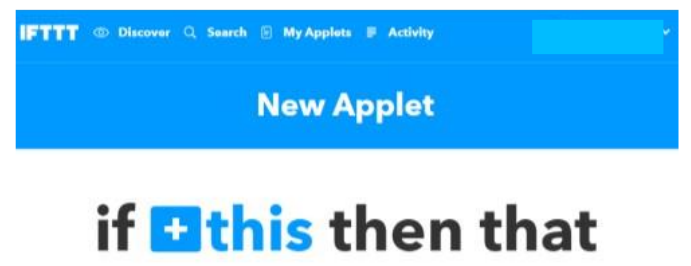

\section{Relay}

- Gambar 4. Tampilan depan If This Then That

Relay adalah sakelar mekanik yang dikendalikan secara elektronik (elektro magnetik). Sakelar pada relay dapat terjadi perubahan posisi off ke on pada saat arus listrikpada kumparan relay tersebut. Relay mempunyai dua bagian utama yaitu sakelar kontak mekanik dan pembangkit elektromagnetik (kumparan). Sakelar pada relay dikendalikan menggunakan tegangan listrik yang diberikan ke kumparan yang menghasilkan elektro magnetik untuk menarik tuas sakelar relay. Kumparan adalah gulungan kawat yang dapat arus listrik, sedang saklar kontak mekanik adalah sakelar yang posisi pergerakannya tergantung pada ada tidaknya arus listrik yang mengalir di kumparan. [8]

Relay biasanya memiliki tiga kontak. Kontak biasanya diberi label Common (COM), Normally Open $(N O)$,dan Normally Close (NC). Pada NC, kontak akan terhubung ke kontak COM ketika coil tidak diberi daya. Pada NO, kontak akan terhubung hanya jika ketika ada daya yang diberikan pada coil. Ketika daya listrik diberikan, maka COM akan terhubung dengan kontak NO dan kontak NC dibiarkan terputus. [9]

\section{A. Diagram Fishbone}

\section{METODE PENELITIAN}

Berikut gambar di bawah ini merupakan diagram Fishbone dimana ada empat proses yaitu : Hardware dan Software, Perancangan, Program, dan Pengujian. 


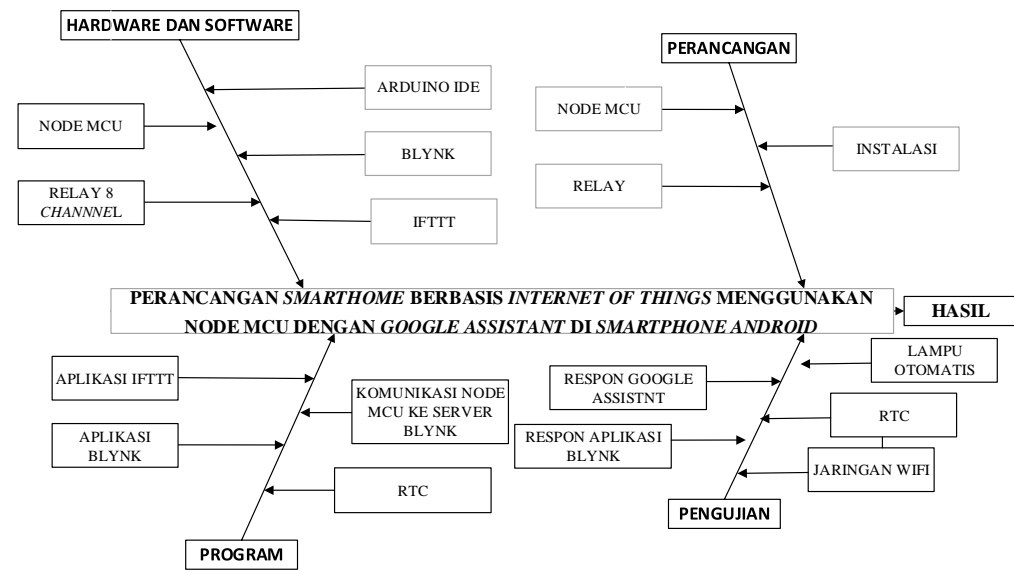

- Gambar 5. Diagram Fishbone

\section{B. Alat dan bahan}

Penlitian ini membutuhkan beberapa alat dan bahan yang akan digunakan dalam perancangan smarthome berbasis Internet of Things Menggunakan NodeMCU dengan Google Assistant di smartphone android. Alat dan bahan yang diperlukan adalah sebagai berikut:

Tabel 1. Tabel Alat dan Bahan

\begin{tabular}{ccc}
\hline No & Alat dan Bahan & Jumlah \\
\hline 1 & NodeMCU & 1 \\
\hline 2 & Relay 8 Channel & 1 \\
\hline 3 & Kabel Jumper & Secukupnya \\
\hline 4 & Fitting Lampu & 2 \\
\hline 5 & Stop Kontak & 1 \\
\hline 6 & Box & 1 \\
\hline 7 & Obeng & 1 \\
\hline 8 & Tang potong & $34 \mathrm{~cm} \mathrm{x} \mathrm{24cm}$ \\
\hline 9 & Akrilik &
\end{tabular}

\section{Diagram Blok Sistem}

Pada penelitian ini, dibutuhkan NodeMCU sebagai mikrokontroller, yang berfungsi untuk mengendalikan peralatan listrik, mengolah data, mengirim dan menerima data ke server Blynk. IFTTT sendiri sebagai penghubung antara 2 buah platform yaitu Blynk dan Google Assistant.

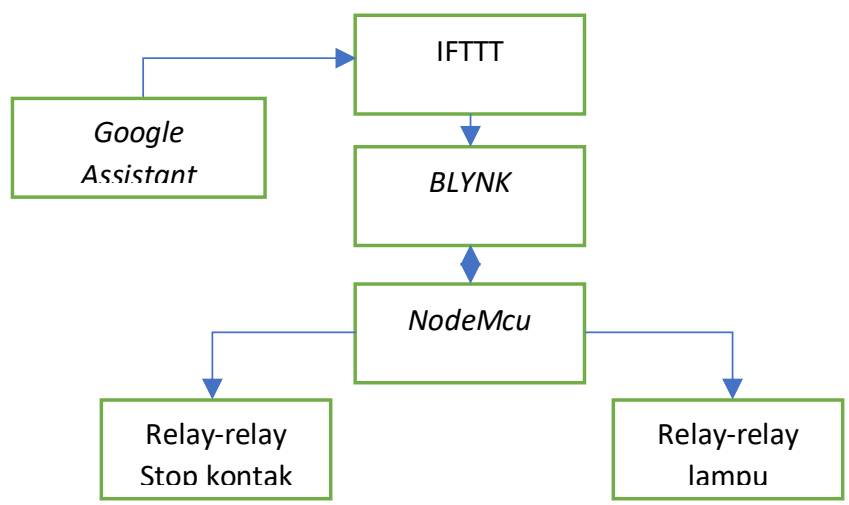

Gambar 6. Diagram Blok Sistem

Diagram Blok sistem pada penelitian ini dibuat berdasarkan kebutuhan dari sistem smarthome itu sendiri, semua blok-blok dalam sistem akan saling terhubung secara dua arah maupun satu arah, hubungan dua arah hanya terdapat pada blok Blynk dan NodeMCU, dikarenakan disana akan terjadi pertukaran data secara sinkron antara keduanya, sedangkan yang lainya hanya terhubung satu arah. Google Assistant hanya bisa 
mengirim data ke IFTTT dan tidak bisa sebaliknya, begitu pula IFTTT hanya bisa mengirim data ke Blynk, tidak bisa sebaliknya.

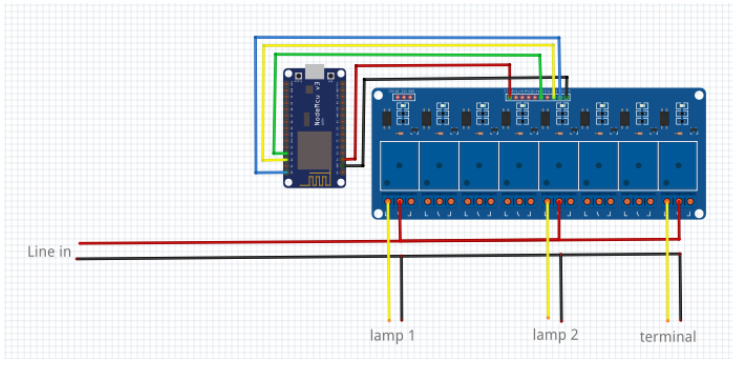

- Gambar 7. Rangkaian Peralatan

Gambar 3.3 menunjukkan rangkaian yang digunakan pada peralatan Smarthome. Relay dan NodeMCU akan terhubung secara langsung melalui pin-pin yang ada pada NodeMCU dan Relay. Pada NodeMCU dan relay terhubung dengan listrik DC, sedangkan pada bagian kontak relay terhubung dengan listrik AC. Listrik AC diambil langsung dari sumber listrik bisa berupa sumber listrik milik PLN dengan tegangan 220V. Listrik AC tersebut masuk ke kontak-kontak Relay dan kemudian akan disalurkan ke beban.

\section{A. Hasil Perancangan}

\section{HASIL DAN PEMBAHASAN}

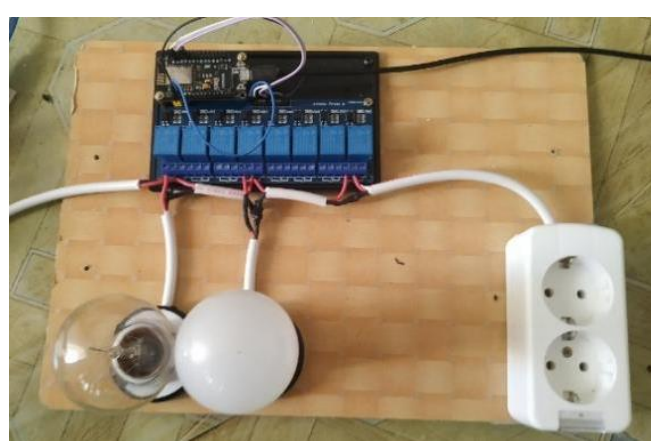

- Gambar 8. Hasil Perancangan

Gambar 8 adalah hasil akhir perangkat keras dari Perancangan Smarthome Berbasis Internet of Things Menggunakan NodeMcu. Di dalam perangkat keras yang dibuat, terdapat 2 perangkat utama yaitu NodeMcu sebagai mikrokontroler yang memungkinkan untuk terkoneksi ke sebuah jaringan wifi yang tersambung ke internet, dan sebuah modul relay 8 chanel yang digunakan untuk memutus maupun menyambungkan arus listrik ke beban yang akan dipasangkan ke dalam sistem smarthome ini. Sistem Smarthome Berbasis Internet of Things Menggunakan NodeMcu ini digunakan untuk mengendalikan beban berupa 2 buah lampu dan 1 buah stop kontak yang terhubung ke relay chanel 1, 2, dan 4. Dengan konfigurasi chanel 1 dan 2 sebagai pengendali untuk lampu, dan chanel 4 sebagai pengendali untuk sebuah stop kontak. Relay 8 chanel terhubung dengan NodeMCU dengan konfigurasi pin D0 terhubung ke relay chanel 1, pin D3 terhubung dengan relay chanel 2, dan pin D2 terhubung ke relay chanel 4.

Tabel 2. Konfigurasi hubung perangkat

\begin{tabular}{ccc}
\hline NodeMcu Pin & Relay Chanel & Beban \\
\hline D0 & Chanel 1 & Lampu \\
\hline D2 & Chanel 1 & Stop Kontak \\
\hline D3 & Chanel 1 & Lampu \\
\hline
\end{tabular}

\section{B. Hasil Perancangan Perangkat Lunak}

Perangkat lunak pada penelitian ini terbagi menjadi beberapa macam yaitu perangkat lunak atau program yang di tulis pada NodeMcu sebagai kontroller dari Smarthome, perangkat lunak aplikasi Android Blynk sebagai Interface dari Smarthome dan sebagai server yang menghubungkan antara NodeMcu dan IFTTT, dan perangkat lunak IFTTT yang berfungsi untuk mengatur perintah dan respon Google Assistant dan perintah tersebut akan diteruskan ke aplikasi Blynk. 


\section{Implementasi Interface Smarthome Blynk}

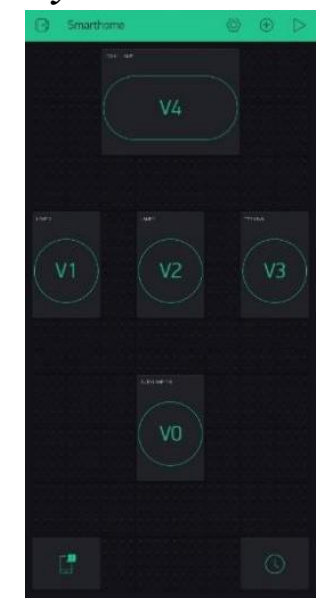

- Gambar 9. Interface Smarthome aplikasi Blynk

Aplikasi Blynk digunakan sebagai Interface dari Smarthome, dengan beberapa kontrol diantaranya yaitu kontrol untuk lampu 1, lampu 2 dan untuk stop kontak, selain itu pada aplikasi Blynk dibuat pula sebuah tombol untuk mengaktifkan semua lampu secara sekaligus dan tombol untuk megaktifkan program penghidupan lampu otomatis. Kontrol pada aplikasi Blynk terhubung dengan peralatan melalui Virtual pin yang sudah tersingkron ke program untuk mengendalikan pin pada NodeMcu yang menuju ke relay untuk mengendalikan peralatan listrik rumah. Server Blynk memili IP (internet Protocol) Address publik yang dapat diakases langsung, IP Addres nya adalah 188.166.206.43.

Tabel 3. Konfigurasi Interface Aplikasi Blynk

\begin{tabular}{ccc}
\hline Interface aplikasi Blynk & Virtual pin Blynk & Peralatan yang dikendalikan \\
\hline Auto lamp & V0 & Lampu 1 dan 2 \\
\hline Lamp 1 & V1 & Lampu 1 \\
\hline Lamp 2 & V2 & Lampu 2 \\
\hline Terminal & V3 & Terminal \\
\hline All lamp & V4 & Lampu 1 dan 2
\end{tabular}

\section{Implementasi Perintah dan respon Google Assistant dengan IFTTT}

IFTTT digunakan sebagai penghubung antara server Blynk dan Google Assistant, Pada Platform IFTTT dapat diatur perintah dan respon yang pada Google Assistant, perintah yang di atur terlihat pada halaman utama IFTTT

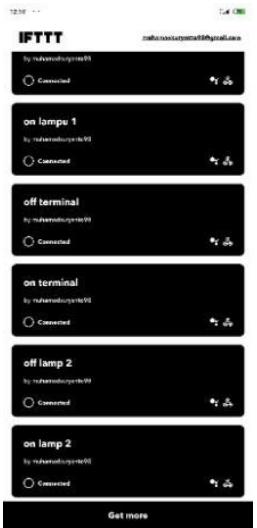

- Gambar 10. Tampilan pada IFTTT

Perintah yang sudah dibuat pada IFTTT dapat Diakses melalui Google Assitant, dan direspon sesuai dengan yang sudah diatur pada platform IFTTT. 


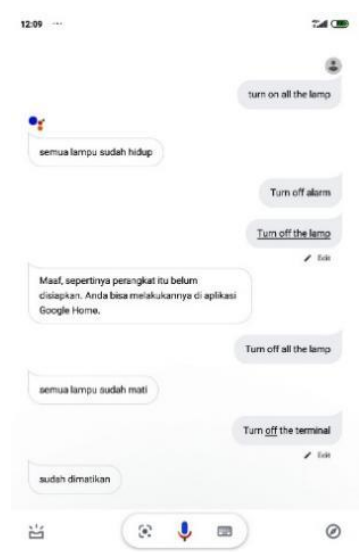

- Gambar 11. Tampilan Perintah suara pada aplikasi Google Assistant

Perintah suara suara pada Google Assistant dapat diatur dengan sedemikian rupa sehingga mudah dilafalkan walaupun menggunakan bahasa Inggris dalam pengucapannya. Perintah suara pada IFTTT hanya bisa dalam bahasa Inggris sedangkan untuk respon dari perintah suara bisa bahasa Indonesia maupun bahasa inggris.

- Tabel 4. Perintah suara dan respon suara Google Assistant

\begin{tabular}{ccc}
\hline Perintah suara & Respon suara & Perintah peralatan \\
\hline Turn on lamp one & Lamp 1 on & Lampu 1 menyala \\
\hline Turn off lamp one & Lamp 1 off & Lampu 1 mati \\
\hline Turn on lamp two & Lamp 2 on & Lampu 2 menyala \\
\hline Turn off lamp two & Lamp 2 off & Lampu 2 mati \\
\hline Turn on the terminal & Terminal on & Terminal menyala \\
\hline Turn off the terminal & Terminal on & Terminal mati \\
\hline Turn on all light & All lamp on & Semua lampu menyala \\
\hline Turn off all light & All lamp off & Semua lampu mati \\
\hline Turn on auto lamp & Auto lamp on & Lampu otomatis diaktifkan \\
\hline Turn off auto lamp & Auto lamp off & Lampu otomatis dimatikan \\
\hline
\end{tabular}

\section{Analisa dan Pengujian}

Pengujian penelitian ini dibagi menjadi lima pengujian yaitu, pengujian perintah suara dari Google Assistant, pengujian Wifi, pengujian penggunaan Aplikasi Blynk, pengujian RTC, dan pengujian program penghidupan lampu otomatis.

1. Pengujian respon Perintah suara dari Google Assistant

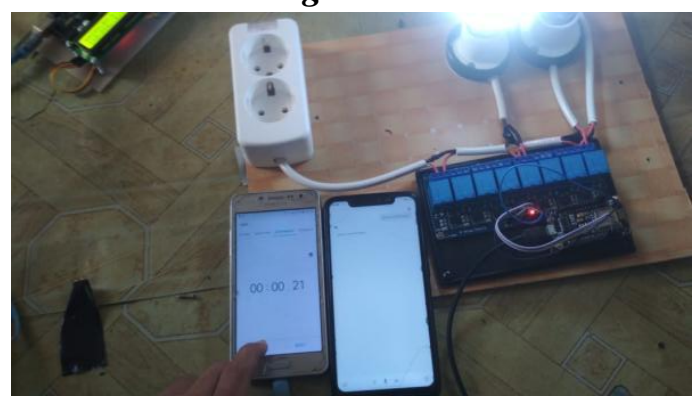

- Gambar 12. Pengujian respon Perintah suara dari Google Assistant

Tujuan dari pengujian respon Perintah suara dari Google Assistant untuk melihat fungsionalitas pada sistem dalam proses input perintah suara pada Google Assistant di Smartphone Android yang kemudian perintah suara tersebut dikirim ke Server Blynk dan diteruskan ke NodeMcu. 
- Tabel 5. Hasil Pengujian respon Perintah suara dari Google Assistant

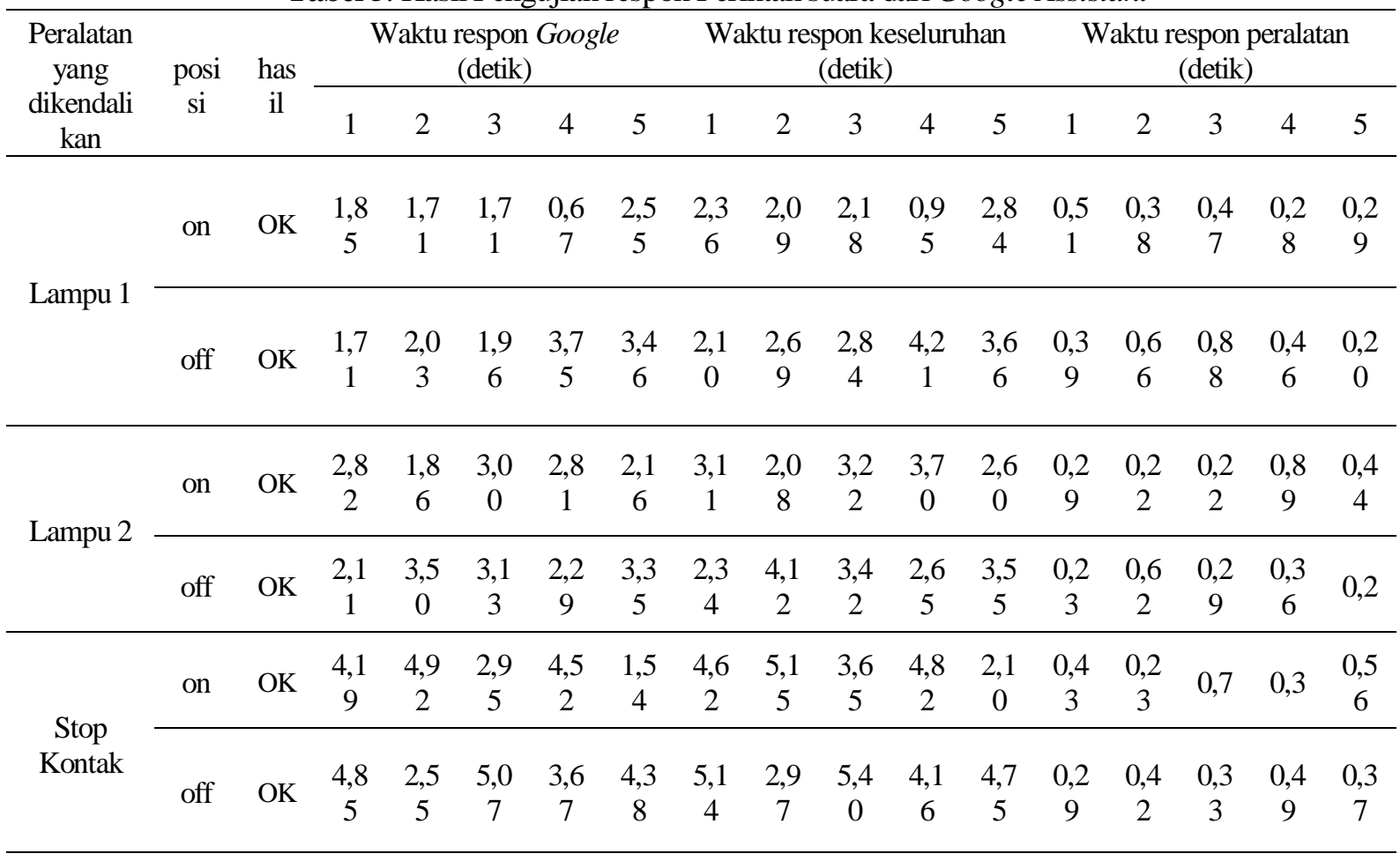

Data pengujian diatas menunjukan bahwa waktu respon keseluruhan Google Assistant dapat mengirim perintah dengan paling lama 5,14 detik, dan paling cepat 0,95 detik. Tabel diatas menunjukkan waktu respon dari Google untuk mengetahui perintah yang diucapkan paling lama 5,05 detik dan paling cepat 0,67 detik. Data perintah dari Google dikirim ke perangkat melalui server Blynk dengan waktu respon rata rata 0,412 detik.

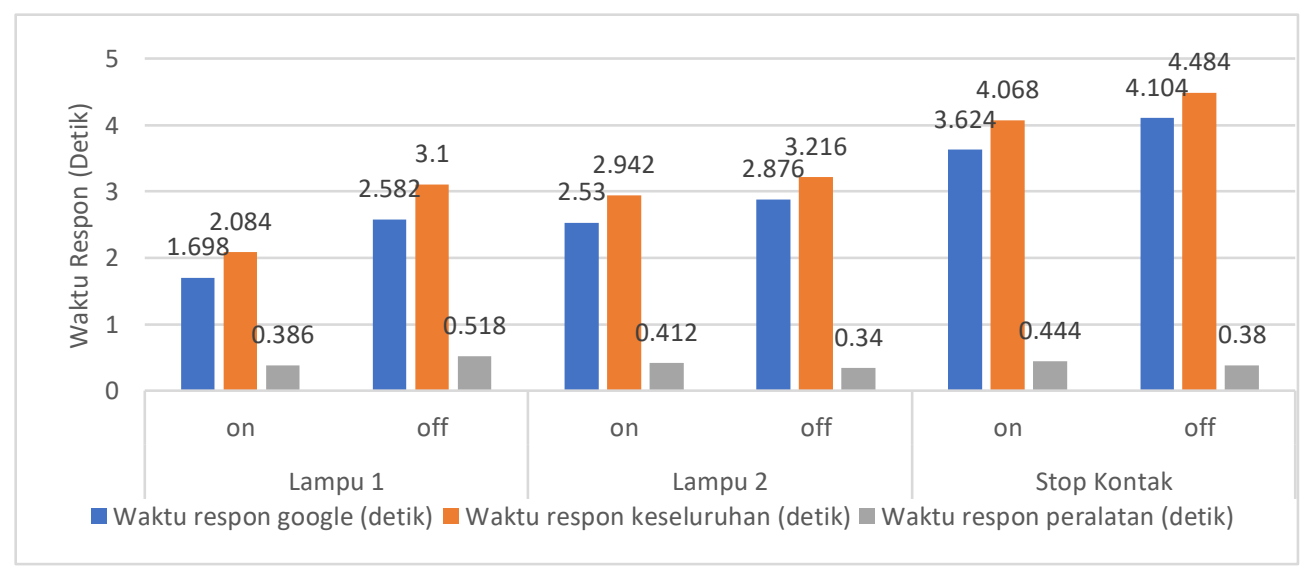

- Gambar 13. Grafik Pengujian respon Perintah suara dari Google Assistant

Pengujian menunjukkan bahwa perintah suara dari Google Assistant yang dibuat melalui Platform IFTTT dapat bekerja dengan cepat dan akurat. variasi respon keseluruhan sangat dipengaruhi dari kecepatan respon Google dalam mengetahui perintah apa yang diucapkan. Lambatnya Google dalam mengetahui perintah yang diucapkan salah satunya dapat dipengaruhi oleh cara pengucapan perintah yang kurang pas.

\section{Pengujian respon kendali melalui Aplikasi Blynk}

Tujuan dari pengujian respon kendali melalui Aplikasi Blynk untuk melihat fungsionalitas pada sistem dalam proses input kendali pada Interface pada Aplikai Blynk yang yang disinkronkan dengan NodeMcu. Keberhasilan pengujian diberi tanda "OK" sedangkan pengujian yang tidak berhasil diberi "Gagal", pengujian dilakukan sebanyak 5 kali.

- Tabel 6. Pengujian respon kendali melalui Aplikasi Blynk 
Perancangan Smarthome Berbasis Internet of Things Menggunakan NodeMCU dengan Google Assistant di Smartphone Android

\begin{tabular}{ccccccccc}
\hline \multirow{2}{*}{$\begin{array}{c}\text { Peralatan yang } \\
\text { dikendalikan }\end{array}$} & \multirow{2}{*}{ posisi } & \multirow{2}{*}{ hasil } & \multicolumn{7}{c}{ Waktu respon peralatan (detik) } \\
\cline { 4 - 9 } & & & 1 & 2 & 3 & 4 & 5 & Rata-rata \\
\hline \multirow{2}{*}{ Lampu 1 } & on & OK & 0,27 & 0,21 & 0,28 & 0,28 & 0,20 & 0,248 \\
\cline { 2 - 9 } & off & OK & 0,20 & 0,27 & 0,27 & 0,21 & 0,34 & 0,258 \\
\hline \multirow{2}{*}{ Lampu 2 } & on & OK & 0,86 & 0,26 & 0,20 & 0,27 & 0,32 & 0,382 \\
\cline { 2 - 9 } & off & OK & 0,32 & 0,21 & 0,27 & 0,21 & 0,20 & 0,242 \\
\hline \multirow{2}{*}{ Stop Kontak } & on & OK & 0,40 & 0,33 & 0,20 & 0,40 & 0,43 & 0,352 \\
\cline { 2 - 8 } & off & OK & 0,33 & 0,27 & 0,47 & 0,77 & 0,30 & 0,428 \\
\hline
\end{tabular}

Pengujian waktu resppon dilakukan sebanyak 5 kali. Dapat dilihat bahwa Aplikasi Blynk dapat mengirim perintah menghidupkan lampu 1 dengan kecepatan rata-rata 0,284 detik, sedangkan untuk mematikan nya membuthkan waktu rata rata 0,258 detik. Lampu 2 juga mempunyai waktu respon yang sangat cepat yaitu rata-rata 0,382 detik untuk menghidupkan, dan 0,242 detik untuk mematikan. Waktu respon stop kontak saat dihidupkan rata-rata 0,352 detik, dan saaat dimatikan rata-rata 0,428 detik.

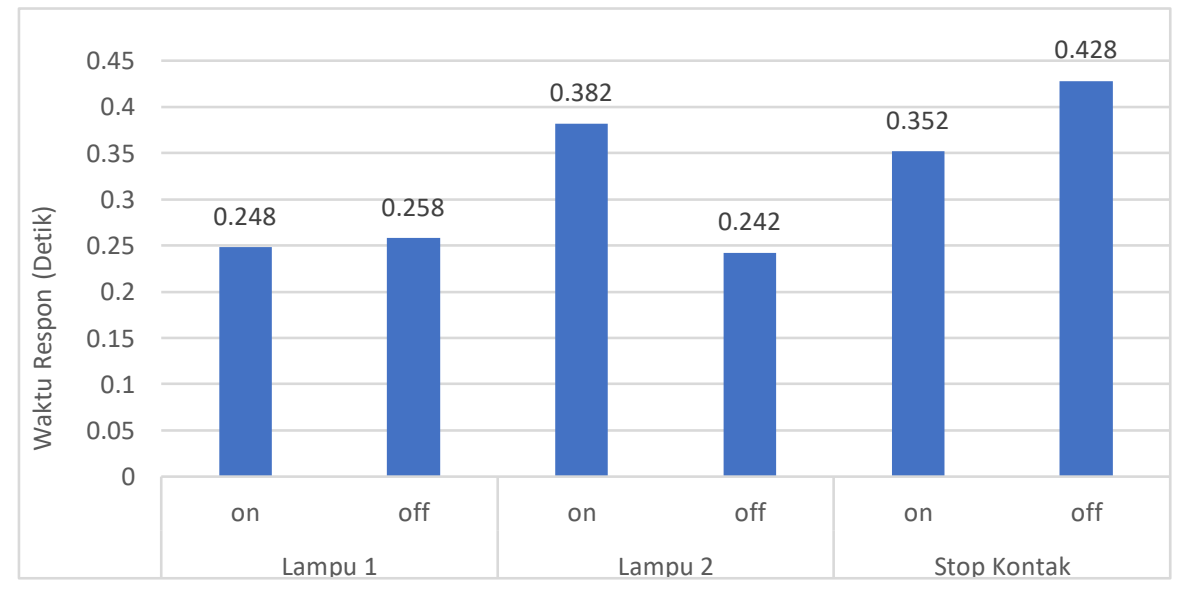

- Gambar 14. Grafik pengujian respon Perintah suara dari aplikasi Blynk

Dari gambar 14 dapat dilihat bahwa waktu respon rata rata berkisar 0,248 detik hingga 0,428 detik. Dari pengujian diatas dapat disimpulkan bahwa bahwa kendali dari aplikasi Blynk dapat bekerja dengan cepat dan akurat, dengan waktu respon yang sangat kecil dan cukup stabil.

\section{Pengujian Jaringan Wifi}

Tujuan dari pengujian Jaringan Wifi ini untuk melihat seberapa jauh jarak maksimal peralatan yang sudah dibuat dari pemancar jaringan Wifi agar dapat berfungsi dengan baik, dalam hal ini pengujian dilakukan dengan menggunakan koneksi Wifi dari Smartphone, dengan IP Addres lokal 192.168.43.102, dan IP Address publik 114.125.251.171. Pengujian ini dilakukan dengan kondisi Line Of Sight (LOS), yaitu antara pemancar jaringan wifi dan peralatan ini dalam posisi satu garis tanpa terhalang benda apapun. Pengujian dilakukan dengan mengirim satu perintah kepada peralatan dengan aplikasi Blynk maupun perintah suara Google Assitant. Keberhasilan pengujian diberi tanda "OK" sedangkan pengujian yang tidak berhasil diberi "Gagal".

Tabel 7. Pengujian Jaringan Wifi

\begin{tabular}{ccccc}
\hline \multirow{2}{*}{ Jarak } & \multirow{2}{*}{ hasil } & \multicolumn{2}{c}{ Waktu respon Google Assistan } & Waktu respon aplikasi \\
\cline { 3 - 4 } & & Respon Google & Respon keseluruhan & Blynk \\
\hline 2 Meter & OK & 1,46 & 1,77 & 0,86 \\
\hline 4 Meter & OK & 2,82 & 3,32 & 0,60 \\
\hline 6 Meter & OK & 1,52 & 1,73 & 0,47 \\
\hline 8 Meter & OK & 3,02 & 3,32 & 0,47 \\
\hline 10 Meter & OK & 4,21 & 4,73 & 0,40 \\
\hline 12 Meter & OK & 2,62 & 3,08 & 0,47 \\
\hline 14 Meter & OK & 2,02 & 2,59 & 0,53 \\
\hline 16 Meter & OK & 3,94 & 4,37 & 0,47 \\
\hline
\end{tabular}




\begin{tabular}{ccccc}
\hline 18 Meter & OK & 2,48 & 2,92 & 0,73 \\
\hline 20 Meter & OK & 3,87 & 4,23 & 0,52 \\
\hline 22 Meter & OK & 3,26 & 3,85 & 0,91 \\
\hline 24 Meter & Gagal & - & - & - \\
\hline
\end{tabular}

Pada hasil pengujian dapat dilihat bahwa peralatan hasil perancangan ini dapat bekerja dengan maksimal radius maksimal 22 meter dari sumber wifi. Dari hasil pengujian juga dapat dilihat bahwa jarak radius penerimaan wifi tidak terlalu berpengaruh terhadap waktu respon peralatan.

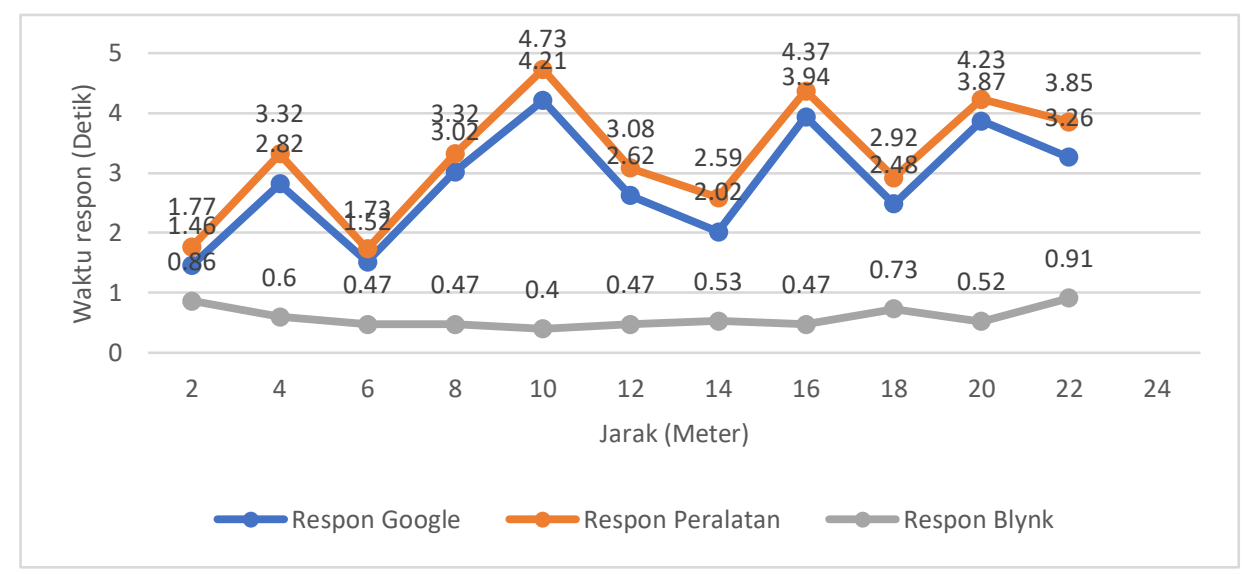

- Gambar 15. Grafik Pengujian Jaringan Wifi

Dari gambar 15 dapat dilihat bahwa jarak tidak terlalu mempengaruhi lamanya waktu respon ke peralatan, tetapi jarak yang terlalu jauh dari sumber wifi akan memutus koneksi ke jaringan, sehingga peralatan smarthome tidak dapat terhubung ke Smartphone melalui jaringan Internet.

\section{Pengujian RTC}

Tujuan dari pengujian untuk mengetahui keakuratan dari RTC yang ada dalam peralatan yang dibuat, faktor keberhasilan dari pengujian ini adalah seberapa jauh perbedaan antara waktu RTC yang ada di peralatan dan waktu yang sebenarnya.

- Tabel 8. Pengujian RTC

\begin{tabular}{ccc}
\hline Waktu RTC & Waktu sebenarnya & Selisih \\
\hline $13: 36: 47$ & $13: 36: 48$ & 1 Detik \\
\hline $13: 36: 57$ & $13: 36: 58$ & 1 Detik \\
\hline $13: 37: 07$ & $13: 37: 08$ & 1 Detik \\
\hline $09: 35: 51$ & $09: 35: 52$ & 1 Detik \\
\hline $09: 36: 01$ & $09: 36: 02$ & 1 Detik \\
\hline $09: 36: 11$ & $09: 36: 12$ & 1 Detik \\
\hline
\end{tabular}

Pada tabel hasil pengujian dapat dilihat bahwa RTC yang terdapat pada peralatan dapat bekerja dengan baik dengan selisih waktu dari waktu sebenarnya sebesar 1 detik. Selisih waktu 1 detik tersebut dapat diabaikan dan tidak mempengaruhi performansi pada peralatan Smarthone dalam penelitian ini, karena RTC hanya sebagai referensi waktu yang dipakai untuk peralatan agar dapat berjalan sebagaimana semestinya.

\section{Pengujian program lampu otomatis}

Tujuan dari pengujian ini adalah untuk melihat keoptimalan program lampu otomatis yang sudah ada pada peralatan Smarthome pada penelitian ini. Faktor keberhasilan dari pengujian ini adalah ketepatan waktu penghidupan lampu otomatis dengan waktu yang sudah ditentukan pada program. Pada program lampu otomatis, semua lampu akan menyala pada jam 17.00 yaitu pada sore hari, dan semua lampu akan mati pada jam 6.00 pada keesokan paginya.

Tabel 9. Pengujian program lampu otomatis

$\begin{array}{lll}\text { Program yang berjalan } & \text { Waktu program } & \text { Waktu saat program berjalan }\end{array}$




\begin{tabular}{ccc}
\hline Lampu hidup otomatis & 17.00 & 17.01 \\
\hline Lampu mati otomatis & 06.00 & 06.01 \\
\hline
\end{tabular}

Pada hasil pengujian dapat dilihat bahwa waktu program lampu otomatis saat lampu dihidupkan otomatis maupun saat dimatikan otomatis berjalan berbeda 1 detik dari waktu yang sudah ditentukan. Perbedaan waktu 1 detik ini dikarenakan keterlambatan 1 detik pada RTC pada peralatan yang sudah diuji sebelumnya. Keterlambatan waktu yang sama antara program lampu otomatis dan RTC dikarenakan program lampu otomatis ini mengambil waktu dari RTC sebagai referensi untuk menghidupkan maupun mematikan semua lampu.

\section{A. Kesimpulan}

\section{KESIMPULAN DAN SARAN}

Kesimpulan yang dapat diambil dari penelitian ini adalah

1. Android device dengan Google Assistant dapat digunakan untuk pengolahan perintah suara untuk nantinya diproses menjadi perintah untuk mengendalikan peralatan listrik. Berdasarkan pengujian yang dilakukan, perintah suara dalam proses penerimaan suara oleh Google Assistant, dapat berjalan dengan baik selama perintah suara diucapkan dengan baik dan benar dalam bahasa Inggris. hasil pengujian fungsional dinyatakan berhasil dengan baik.

2. Berdasarkan pengujian respon aplikasi Blynk yang dilakukan, hasil pengujian fungsional dinyatakan berhasil dengan tingkat keberhasilan $100 \%$, dengan waktu jeda rata-rata kurang dari satu detik

3. Berdasarkan pengujian Jaringan Wifi yang dilakukan, dengan IP Addres lokal 192.168.43.102, dan IP Address publik 114.125.251.171. Hasil pengujian fungsional dinyatakan berhasil dengan kondisi LOS, jarak terjauh peralatan dan wifi agar dapat berfungsi dengan baik yaitu 22 Meter.

4. Berdasarkan pengujian yang dilakukan pada RTC, RTC bekerja untuk memberikan informasi tentang waktu saat ini yang kemudian digunakan sebagai referensi waktu untuk menjalankan perintah penghidupan lampu otomatis. Hasil pengujian fungsional dinyatakan berhasil dengan selisih waktu RTC dan waktu sebenarnya sebesar 1 detik.

\section{B. Saran}

Untuk penggunaan perintah suara dipenelitian selanjutnya dapat menggunakan bahasa Indonesia karena dengan menggunakan bahasa inggris terdapat beberapa kekeliruan dalam penangkapan perintah yang diucapkan oleh Google Assistant.

\section{DAFTAR PUSTAKA}

[1] F. C. I. L. Herin and . H. Pangaribuan, "VOICE CONTROL SEBAGAI PENGENDALI PERALATAN ELEKTRONIK BERBASIS NODEMCU," 2019.

[2] H. A. Rochman, . R. Primananda and . H. Nurwasito, "Sistem Kendali Berbasis Mikrokontroler Menggunakan Protokol MQTT pada Smarthome," 2017.

[3] M. K. A. Putra, S. . R. Akbar and G. E. Setyawan, "Perancangan Sistem Keamanan Pada Smart Home Menggunakan Voice Command Dengan Konektivitas Bluetooth," 2018.

[4] A. R. Azka, E. D. Marindani and R. . D. Nyoto, "Rancang Bangun Sistem Pengendali Smarthome menggunakan Mikrokontroler dengan Speech Command pada Smarthome Android," 2018.

[5] A. D. Pangestu, . F. Ardianto and B. Alfaresi, "SISTEM MONITORING BEBAN LISTRIK BERBASIS ARDUINO NODEMCU ESP8266," 2019.

[6] Arafat, "SISTEM PENGAMANAN PINTU RUMAH BERBASIS Internet Of Things (IoT) Dengan ESP8266," 2016.

[7] A. Setiawan, W. W. Mustika and T. . B. Adji, "PERANCANGAN CONTEXT-AWARE SMART HOME DENGAN MENGGUNAKAN INTERNET OF THING," 2016.

[8] A. Satriadi, Y. Christiyono and W. , "PERANCANGAN HOME AUTOMATION BERBASIS NodeMCU," 2019.

[9] M. A. Ashari and L. Lidyawati, "IOT BERBASIS SISTEM SMART HOME MENGGUNAKAN NODEMCU V3," 2019. 
[10] E. Hesti and Adewasti, "APLIKASI ANDROID SEBAGAI PENGONTROL JARAK JAUH SMARTHOME DENGAN KONEKSI JARINGAN INTERNET," 2018. 